

\title{
Dispositivo para Medição da Pressão do Arco e sua Aplicação no Estudo do Processo TIG
}

\section{(Device for the Arc Pressure Measurement and its Application on the TIG Welding Process Study)}

\author{
Tiago Vieira da Cunha ${ }^{1}$, Carlos Enrique Niño Bohórquez ${ }^{2}$ \\ ${ }^{1}$ Universidade Federal de Santa Catarina, Campus Joinville, Joinville, Santa Catarina, Brasil. t.cunha@ufsc.br \\ ${ }^{2}$ Universidade Federal de Santa Catarina, Campus Universitário Trindade, Florianópolis, Santa Catarina, Brasil. carlos.nino@ufsc.br
}

\section{Resumo}

Diante da importância da pressão de estagnação do arco na formação da poça de fusão ou de defeitos no cordão, e das dificuldades associadas à sua medição, devido, sobretudo, às elevadas temperaturas presentes no arco voltaico, neste trabalho foi realizado o desenvolvimento de um dispositivo destinado à medição dessa pressão e uma aplicação inicial com o objetivo de compreender melhor o comportamento da pressão exercida pelo arco voltaico sobre a superfície da poça de fusão. Este estudo contempla a realização de ensaios visando identificar a distribuição radial de pressão do arco, bem como a sua magnitude em função de algumas variáveis de soldagem, a saber: distância eletrodopeça e tamanho do bocal de gás. Os resultados indicam que a pressão de estagnação do arco é fortemente influenciada pela distância eletrodopeça e, em menor grau, pelo tamanho do bocal de gás, e sua distribuição radial pode ser descrita por uma curva gaussiana.

Palavras-chave: Pressão de estagnação; Medição de pressão; Arco voltaico.

Abstract: Considering the importance of the stagnation pressure of the arc in the formation of the weld pool or defects in the weld bead, and the difficulties associated with its measurement, mainly due to the high temperatures present in the arc, there was developed in this work a device designed to measure this pressure and an initial application in order to better understand the behavior of the pressure exerted by the arc on the surface of the weld pool. Experiments were realized in this study to identify the radial distribution of the stagnation pressure and its magnitude according to some welding variables, namely piece-electrode distance and size of the gas nozzle. The results indicate that the stagnation pressure of the arc is strongly influenced by the piece-electrode distance and to a lesser degree, the size of the gas nozzle and its radial distribution can be described by a Gaussian curve.

Key-words: Stagnation pressure; Pressure measurement; voltaic Arc.

\section{Introdução}

Quando uma corrente elétrica percorre um condutor, um campo magnético circunferencial é gerado cujo centro coincide com aquele do condutor. A interação entre esta corrente elétrica e o campo magnético autoinduzido resulta numa força conhecida como força de Lorentz, ou força eletromagnética, cuja direção é radial e orientada para o centro do condutor [1]. Em soldagem, a condução da corrente elétrica ocorre através de um gás ionizado, o plasma, dando origem, assim, ao arco voltaico. Nesse arco, a força de Lorentz, que causa a sua constrição, é equilibrada pelo gradiente de pressão radial do arco que age no sentido oposto.

No arco voltaico de soldagem, a densidade de corrente na região próxima ao eletrodo é maior (da ordem de $10^{7}$ A.m ${ }^{-2}$ [2]) do que na região próxima à superfície da poça de fusão (da ordem de $10^{6} \mathrm{~A} \cdot \mathrm{m}^{-2}$ [2]). Isto faz com que a pressão estática do plasma

Recebido em 06/02/2014, texto final em13/05/2014.

DOI: 10.1590/0104-9224/SI1902.07 próximo ao eletrodo seja maior do que próximo à superfície da peça de trabalho. Como resultado, esta diferença de pressão dá origem a um jato de plasma em direção à peça de trabalho [1,35] independente da polaridade de soldagem. A velocidade desse jato de plasma é da ordem de centenas de metros por segundo [3], com valores máximos próximos ao eletrodo, e decrescendo na medida em que se aproxima da superfície da peça de trabalho [6-8]. Quando este jato de plasma colide com a superfície da poça de fusão o mesmo dá origem a uma pressão de estagnação, conhecida como pressão do arco [3]. Assim, na soldagem, o arco voltaico pode ser considerado não somente uma fonte de calor, mas também uma fonte de força.

A pressão do arco é apontada na literatura como sendo um dos parâmetros que determina a penetração da solda $[3,9]$, e a formação de vários defeitos no cordão [3,10,11] como, por exemplo, o "humping" que surge em elevadas velocidades e correntes de soldagem no processo TIG. Isto faz com que a pressão exercida pelo arco voltaico sobre a superfície da poça de fusão, seja objeto de interesse nos estudos acerca de novos processos e técnicas de soldagem que visam o aumento da produtividade, da penetração ou a obtenção de cordões isentos de defeitos. 
Neste sentido, ao serem empregadas correntes de soldagem de baixa intensidade, comuns nas aplicações manuais, é desejável que a pressão do arco seja elevada, de modo a se obter maiores valores de penetração, pois, um processo que proporciona maiores volumes de material fundido para uma dada condição de soldagem, evidentemente, é mais eficiente e produtivo. Por outro lado, nas aplicações automatizadas, onde o aumento da velocidade de soldagem na busca por maiores índices de produtividade conduz, necessariamente, ao emprego de maiores valores de corrente a fim de possibilitar a manutenção do volume da poça de fusão, as atenções estão voltadas para a redução da pressão do arco a fim de evitar a formação de defeitos no cordão.

Neste contexto, interessa medir a pressão exercida pelo arco sobre a superfície da poça de fusão no sentido de correlacionala com as variáveis de processo. Entretanto, há dificuldades relacionadas à medição desta grandeza associadas, sobretudo, às elevadas temperaturas presentes no arco voltaico e na poça de fusão, o que impossibilita a aplicação direta de sensores comerciais, dada as suas relativas baixas temperaturas máximas de operação. Visando contornar estas dificuldades, em trabalhos disponíveis na literatura $[1,10,12-15]$ é proposta uma técnica de medição da pressão do arco, que embora utilizem diferentes meios para realizar a medição propriamente dita, faz uso de um método comum. Essencialmente, esta técnica baseia-se na medição da pressão exercida pelo arco voltaico sobre um orifício, normalmente de $1 \mathrm{~mm}$ de diâmetro, posicionado na peça de trabalho (ânodo). A peça de trabalho deve ser confeccionada de cobre e refrigerada a água, de modo a evitar a sua fusão e, consequentemente, obstruir o citado orifício. A conexão entre este orifício e o sensor de pressão é então realizada por um tubo prolongador, com o intuito de evitar a exposição do sensor às elevadas temperaturas presentes na região do arco voltaico.

Baseado nesta técnica, este trabalho tem por objetivo promover uma melhor compreensão do comportamento da pressão exercida pelo arco voltaico sobre a superfície da poça de fusão (pressão de estagnação). Assim, foi desenvolvido um dispositivo para realizar a medição da pressão do arco para,

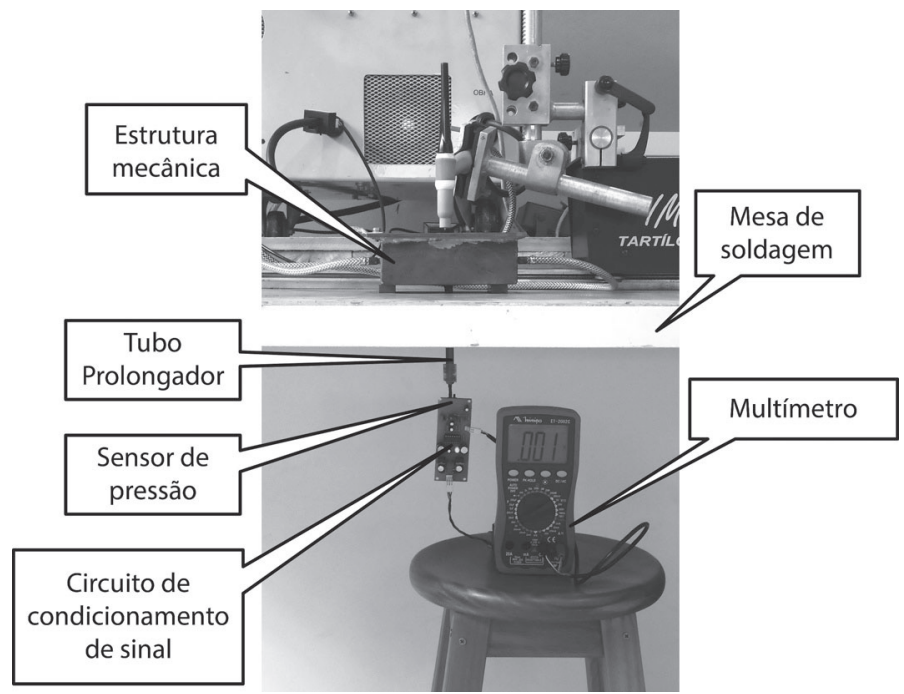

Figura 1. Dispositivo desenvolvido para a medição da pressão do arco na sequência, dar-se início ao estudo da referida pressão, com o levantamento inicial da distribuição radial de pressão e da influência de alguns dos parâmetros de soldagem, a saber: distância eletrodo-peça (DEP) e diâmetro do bocal de gás.

\section{Desenvolvimento do dispositivo de medição}

O desenvolvimento do dispositivo de medição da pressão do arco seguiu a mesma filosofia de equipamentos descritos na literatura. O mesmo é composto por uma estrutura mecânica, um sensor de pressão eletrônico de última geração e um circuito de condicionamento de sinal, que permite a leitura da pressão (em Pascal) diretamente no mostrador de um milivoltímetro. Este dispositivo é mostrado na Figura 1 e abordado em detalhes na sequência.

\subsection{Estrutura mecânica}

A estrutura mecânica do dispositivo de medição é constituída por uma placa de cobre com $4,75 \mathrm{~mm}$ de espessura (127 x 170 $\mathrm{mm}$ ), uma cuba confeccionada em aço carbono e um tubo prolongador de $8,0 \mathrm{~mm}$ de diâmetro interno, também de cobre, conforme detalhado na Figura 2.

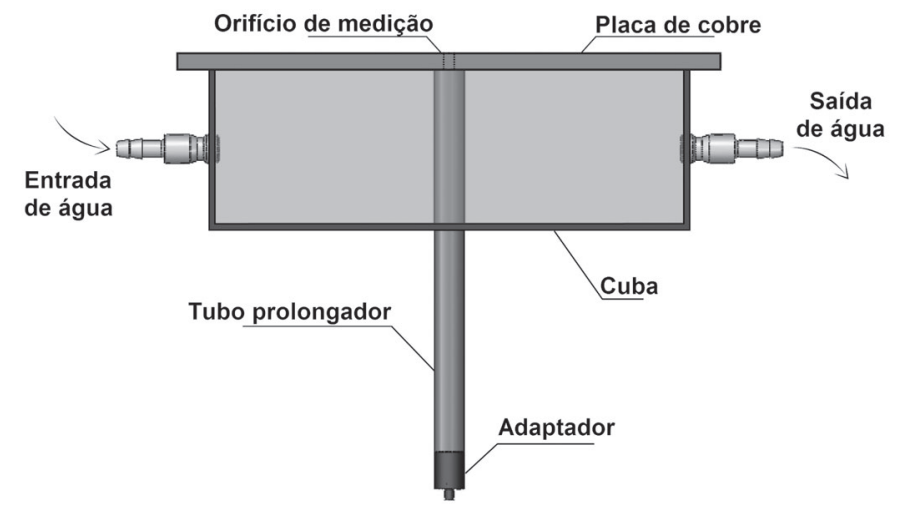

Figura 2. Estrutura mecânica do dispositivo de medição da pressão do arco

Um orifício de $1,0 \mathrm{~mm}$ de diâmetro (denominado neste trabalho de orifício de medição) foi confeccionado no centro geométrico da placa de cobre. Nesta, foi brasado o tubo prolongador concentricamente ao citado orifício. Completando a estrutura, têm se a cuba. Esta, equipada com dois espigões, um de entrada e outro de saída de água, foi brasada em ambos os componentes (placa de cobre e tubo prolongador) para, assim, dar origem a um reservatório de água com capacidade de 0,8 L aproximadamente. Assim, ao ser preenchido completamente, a água do circuito de refrigeração será capaz de refrigerar simultaneamente a placa de cobre (ânodo), sujeita ao calor do arco voltaico, e uma parcela do tubo prolongador.

A extremidade livre do tubo prolongador foi equipada com um adaptador a fim de promover o acoplamento hermético entre o sensor e o volume conectado ao orifício de medição. O comprimento do tubo prolongador foi definido experimentalmente, com a realização de ensaios exploratórios com o propósito de determinar o comprimento mínimo necessário 
para que a temperatura na região interna, próxima ao adaptador, não ultrapassasse a temperatura máxima de operação do sensor empregado $\left(60^{\circ} \mathrm{C}\right)$. Nestes ensaios, um arco voltaico de $80 \mathrm{~A}$ foi estabelecido concentricamente ao orifício de medição, e a temperatura na região interna do tubo prolongador medida após dois minutos de arco aberto. Este tempo foi definido como sendo o tempo necessário para o sistema atingir o equilíbrio térmico. Para viabilizar a medida da temperatura interna do tubo, um sensor de temperatura foi introduzido pelo canal comunicante presente no adaptador. Isto só foi possível uma vez que nestes ensaios o sensor de pressão não foi instalado. Como resultado obteve-se o comprimento mínimo de cerca de $150 \mathrm{~mm}$ como sendo o suficiente para garantir a integridade do sensor de pressão utilizado.

\subsection{Sensor}

Neste desenvolvimento foi empregado o sensor de pressão diferencial MPXV7002DP [16]. Este sensor combina técnicas avançadas de microusinagem e metalização de filmes finos para, assim, promover uma precisa saída de tensão proporcional à diferença de pressão sobre ele aplicada. Suas principais características referem-se à capacidade de medição de pressões compreendidas entre $-2 \mathrm{e}+2 \mathrm{kPa}$, com compensação de temperatura para uma faixa operacional de +10 a $+60{ }^{\circ} \mathrm{C}$ e um erro típico, dentro desta faixa, de 2,5\% quando utilizada a função auto-zero.

Devido à elevada sensibilidade do sensor, esforços mecânicos externos ou até mesmo a sua posição de montagem, podem afetar a leitura da pressão zero. Desse modo, a função auto-zero consiste em armazenar a leitura da pressão zero e subtraí-la da saída de tensão do sensor durante a operação do mesmo. No presente trabalho isto foi realizado manualmente, ajustando-se um trimpot presente no circuito de condicionamento de sinal descrito em detalhes na sequência.

Um revestimento de gel promove o isolamento das conexões elétricas internas do sensor contra as possíveis adversidades do ambiente, ao mesmo tempo em que permite que as pressões presentes nas entradas de medição P1 e P2 sejam transmitidas ao

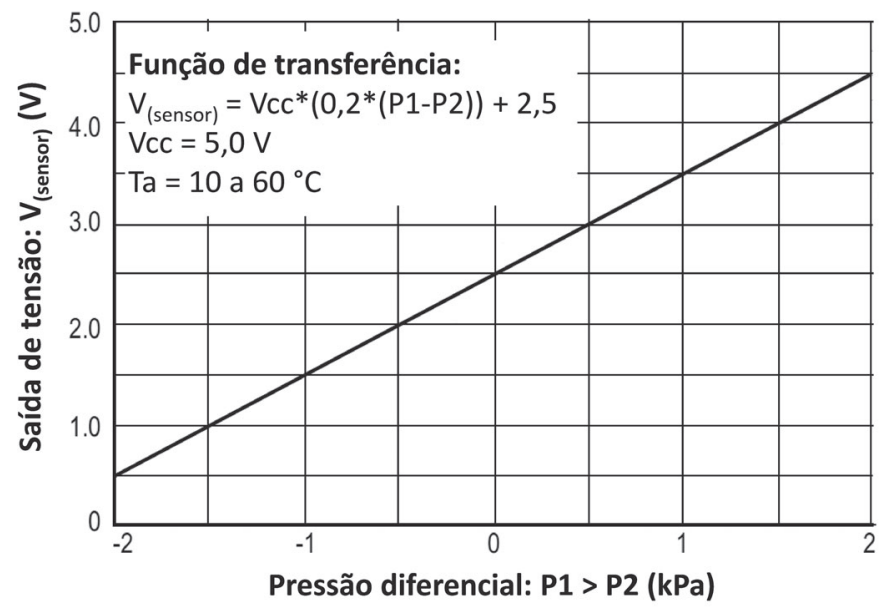

Figura 3. Tensão de saída do sensor de pressão versus pressão diferencial sobre ele aplicada. Adaptado de [16] elemento diferencial de detecção. A entrada P1 está conectada ao orifício de medição, enquanto que a entrada P2 sujeita a pressão atmosférica ambiente. Isto permite a medição da pressão manométrica do arco de forma simples e precisa, uma vez que a pressão ambiente é deduzida diretamente no elemento diferencial de detecção do sensor.

Como se trata de um elemento sensor diferencial, a condição de estabilidade, ou seja, de pressão zero, se dá quando as pressões nas entradas P1 e P2 são iguais. Nesta condição, haverá na saída do sensor uma tensão de 2,5 V. A Figura 3 apresenta a função de transferência do sensor, que corresponde ao sinal de tensão de saída em função da diferença entre as pressões existentes nas suas entradas P1 e P2.

\subsection{Circuito de condicionamento de sinal}

O circuito de condicionamento de sinal desenvolvido é composto, basicamente, por uma fonte de alimentação simétrica e um circuito eletrônico provido de dois amplificadores operacionais dispostos fisicamente num mesmo encapsulamento (TL084), conforme mostrado na Figura 4.

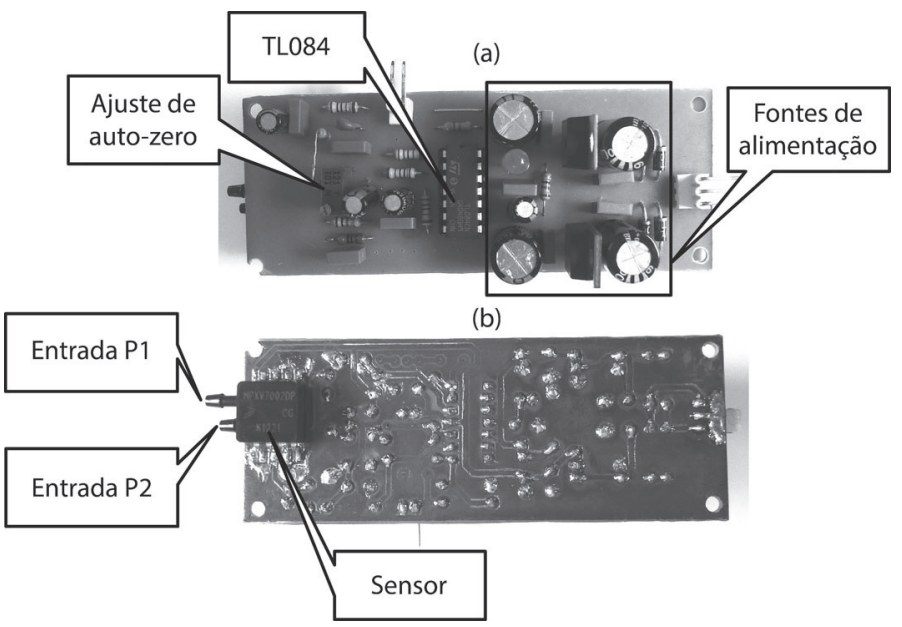

Figura 4. Circuito de condicionamento de sinal. (a) Lado dos componentes e (b) Lado das conexões elétricas.

A principal função deste circuito consiste em realizar o condicionamento do sinal elétrico proveniente da saída do sensor de pressão. Este condicionamento consiste na adequação dos níveis de tensão de saída do sensor, de modo que o valor de pressão medido possa ser lido diretamente no mostrador de um milivoltímetro, ao mesmo tempo em que visa reduzir a intensidade dos ruídos elétricos que por ventura atuem sobre este sinal.

Conforme pode ser visto na Equação1, que retrata a função de transferência do sensor quando este é conectado a uma tensão de alimentação de 5,0 Vcc, sua tensão de saída consiste numa reta com coeficiente angular igual a 1 e coeficiente linear igual a 2,5 .

$$
\mathrm{V}_{\text {(sensor) }}=1 *(\mathrm{P} 1-\mathrm{P} 2)+2,5
$$


Onde P1 e P2 são as pressões presentes nas duas entradas do sensor, em kPa.

Baseado nisso, fez-se necessário aplicar apenas a correção no coeficiente linear da referida função de transferência. Para tanto, foi projetado um circuito eletrônico composto por um subtrator e um circuito de tensão de referência (Figura 5). Este último gera uma tensão de referência estável, cujo valor pode ser ajustado continuamente entre 2,4 e 2,6 V. Esta tensão é então subtraída do valor presente na saída do sensor de pressão. Desse modo, ao mesmo tempo em que se tem a correção da função de transferência para que a tensão apresentada no mostrador do milivoltímetro corresponda diretamente ao valor de pressão medido, tem-se também a função de auto-zero. Pois, na condição de pressão diferencial nula (P1 igual a P2) basta atuar no ajuste da tensão de referência de modo a anular o valor de tensão presente na saída do sensor.

O bloco de circuito identificado como filtro corresponde a um filtro RC passa baixa e um buffer com alta impedância de entrada. Com isso, além de tornar a tensão de saída do sensor mais imune a ruídos, esta, não estará sujeita às impedâncias do restante do circuito. Já o bloco identificado como fonte de alimentação, corresponde a uma fonte de alimentação simétrica de $\pm 5,0 \mathrm{~V}$, necessária para garantir o correto funcionamento do circuito como um todo. Este valor de 5,0 V, principalmente o de sinal positivo, requer especial atenção por interferir diretamente na função de transferência do sensor, conforme visto na Figura 3.

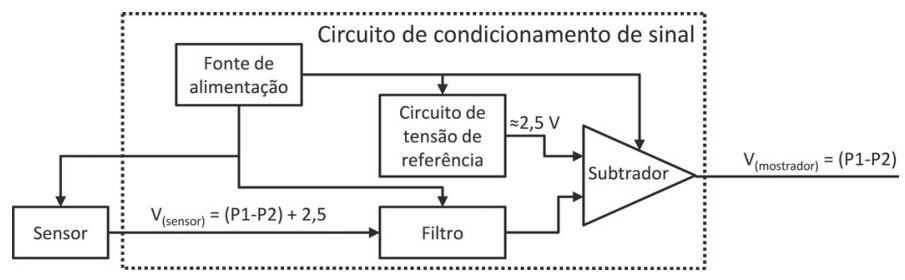

Figura 5. Diagrama de blocos do circuito de condicionamento de sinal

\section{Materiais e Métodos}

Com o dispositivo desenvolvido foram realizados ensaios iniciais com o intuito de correlacionar a pressão do arco com algumas variáveis de soldagem, a saber, à distância eletrodopeça e o tamanho do bocal de gás de proteção, além de obter a distribuição radial dessa pressão.

Nos ensaios cujo objetivo foi o de verificar a influência da distância eletrodopeça, foram empregados valores de DEP de 2 a $6 \mathrm{~mm}$, enquanto que naqueles ensaios onde a variável foi o tamanho do bocal de gás, tamanhos de $\mathrm{N}^{\circ} 4$ a $\mathrm{N}^{\circ} 7$. Nestes ensaios, o arco voltaico foi estabelecido concentricamente ao orifício de medição e, portanto, obtidos os valores da pressão de estagnação no centro do arco. Já para o levantamento da distribuição radial de pressão do arco, a tocha de soldagem foi deslocada sobre uma linha reta, que atravessa o centro do orifício de medição, e a pressão medida a cada avanço de $0,5 \mathrm{~mm}$, realizado manualmente com ajuda de uma escala milimétrica fixada no dispositivo de deslocamento de tocha.

A leitura da pressão foi realizada diretamente no mostrador do milivoltímetro digital conectado ao dispositivo. Com o intuito de minimizar os erros associados à medição da pressão, no intervalo de cada ensaio foi executado o procedimento de auto-zero, descrito anteriormente. Além disso, a fim de obter resultados mais consistentes, todos os valores de pressão apresentados neste trabalho são a média aritmética de três valores obtidos nas mesmas condições de soldagem. Para a realização dos experimentos foram empregadas as condições descritas na Tabela 1.

Tabela 1. Condições de soldagem utilizadas nos ensaios de medição da pressão do arco

\begin{tabular}{|l|c|}
\hline \multicolumn{1}{|c|}{ Variável ou parâmetro } & Valor \\
\hline Corrente de soldagem & $50 \mathrm{~A}$ \\
\hline Distância eletrodo-peça, DEP & $4 \mathrm{~mm}$ \\
\hline Ângulo de afiação do eletrodo & $60^{\circ}$ \\
\hline Diâmetro do eletrodo & $2,4 \mathrm{~mm}$ \\
\hline Tipo do eletrodo & EWTh-2 \\
\hline Avanço do eletrodo* & $3 \mathrm{~mm}$ \\
\hline Vazão de gás & $10 \mathrm{~L} / \mathrm{min}$ \\
\hline Tamanho do bocal de gás & № 5 \\
\hline
\end{tabular}

* Comprimento do eletrodo projetado para fora do bocal de gás

\section{Resultados e Discussão}

\subsection{Influência de DEP sobre a pressão do arco}

O resultado das aquisições da pressão de estagnação no centro do arco para diferentes valores de DEP é apresentado na Figura 6.

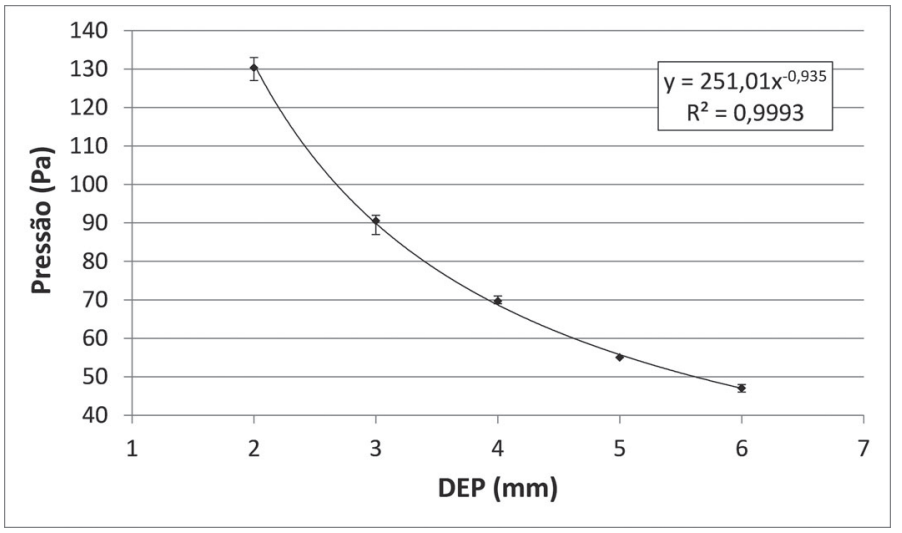

Figura 6. Influência de DEP sobre a pressão do arco

Conforme pode ser visto, a pressão do arco é extremamente dependente da distância eletrodopeça, sendo a pressão maior para menores valores de DEP. Diferentemente do que ocorre com a tensão do arco, cuja relação com o DEP se dá de forma praticamente linear $[17,18]$, a pressão do arco apresenta um comportamento não linear em relação à distância eletrodopeça. Isto é mais evidente com a regressão realizada a partir dos pontos obtidos nos ensaios, que mostra uma função potência 
como sendo a que melhor descreve a relação entre a pressão do arco e a distância entre a ponta do eletrodo e a superfície da peça de trabalho.

O aumento da pressão do arco com a redução de DEP é perfeitamente coerente, se for considerado que a origem desta pressão está associada ao momento do jato de plasma quando este colide com a superfície da poça de fusão. Deste modo, partindo das informações presentes na literatura de que a velocidade do jato de plasma é máxima próxima ao eletrodo [68], é de se esperar, então, que a pressão do arco seja maior nas situações em que a ponta do eletrodo se encontra mais próxima da superfície da peça de trabalho.

Outro ponto a ser considerado, diz respeito aos erros associados às medições de pressão. Conforme pode ser visto, estes aumentam para maiores valores de pressão obtidos. Num primeiro momento, isto poderia estar relacionado ao erro percentual intrínseco do dispositivo de medição. Entretanto, este maior desvio nas medidas se deve, ao fato da pressão do arco ser maior para menores valores de DEP, fazendo com que pequenas variações no ajuste de DEP resultem em alterações significativas no valor de pressão medido. Neste sentido, para DEP igual a $2 \mathrm{~mm}$, variações da ordem de $0,5 \mathrm{~mm}$, por exemplo, são suficientes para acarretar numa alteração da ordem de $20 \mathrm{~Pa}$ na pressão medida.

\subsection{Influência do bocal de gás sobre a pressão do arco}

Partindo do pressuposto de que a pressão do arco é resultado da ação do jato de plasma sobre a superfície da poça de fusão e que, por sua vez, a formação do plasma está intimamente relacionada com a ionização do gás de proteção, é válido pensar que o tamanho do bocal de gás terá, portanto, influência sobre a pressão do arco, uma vez que influi na quantidade de gás disponível para alimentar o arco voltaico. Pois, é de se esperar que, para uma mesma vazão, um bocal de menor tamanho vá dirigir uma maior quantidade de gás de proteção para o arco voltaico, resultando num plasma de maior densidade. Baseado nisso, foram realizadas aquisições da pressão do arco para diferentes tamanhos de bocal de gás, cujos diâmetros e áreas da seção transversal são mostrados na Tabela 2.

Tabela 2. Diâmetro e área de saída do gás de proteção para diferentes tamanhos de bocal de gás

\begin{tabular}{|c|c|c|}
\hline $\begin{array}{c}\text { Tamanho } \\
(\mathrm{N} \text { ㅇ) }\end{array}$ & $\begin{array}{c}\text { Diâmetro interno } \\
(\mathrm{mm})\end{array}$ & $\begin{array}{c}\text { Área interna } \\
\left(\mathrm{mm}^{2}\right)\end{array}$ \\
\hline 4 & 6,6 & 34,2 \\
\hline 5 & 8,2 & 52,8 \\
\hline 6 & 9,7 & 73,8 \\
\hline 7 & 11,0 & 95,0 \\
\hline
\end{tabular}

Os resultados são apresentados na Figura 7, onde é possível verificar que a pressão do arco é visivelmente influenciada pelo bocal de gás, sendo obtidos valores de pressões de cerca de 60 a $80 \mathrm{~Pa}$, para o intervalo de tamanhos de bocal empregados neste estudo. Baseado na hipótese levantada é de se esperar uma relação linear entre a pressão e a área da seção transversal do bocal, já que para menores áreas ter-se-ia uma maior quantidade de gás de proteção sendo proporcionalmente dirigida ao arco voltaico, uma vez que a vazão do gás foi mantida constante. Contudo, o gráfico da Figura 7 a mostra que além desta relação não ser linear, ela é mais bem expressa por uma função potência. Diante deste resultado foi então estabelecida a relação entre a pressão do arco e o diâmetro do bocal de gás. Conforme pode ser visto na Figura 7b, para esta variável a relação encontrada foi linear, fato confirmado pela regressão realizada a partir dos pontos obtidos.
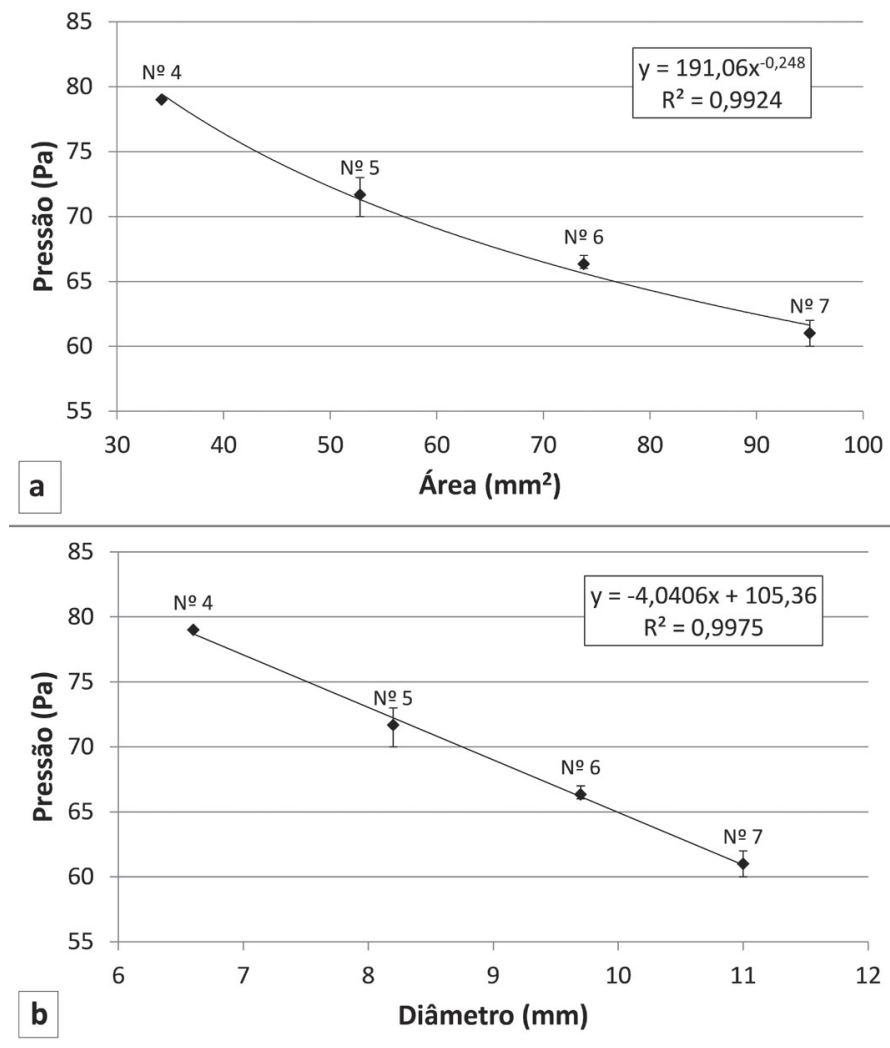

Figura 7. Influência da (a) área e (b) diâmetro do bocal de gás sobre a pressão do arco

Quanto menor o tamanho do bocal, maior a pressão do arco obtida. Este resultado concorda com a hipótese levantada anteriormente, pois ao ser admitida uma maior quantidade de gás de proteção sendo dirigida ao arco voltaico, em virtude da redução da área de saída do gás no bocal, espera-se uma maior densidade do gás de plasma e, consequentemente, um aumento no momento associado ao jato de plasma que impinge a superfície da poça de fusão.

\subsection{Distribuição radial de pressão do arco}

Existem na literatura basicamente duas conjecturas para o formato da distribuição radial de pressão do arco [13]. Uma delas defende que a distribuição radial de pressão deve estar de acordo com as distribuições de densidade de corrente e velocidade do jato de plasma na raiz anódica e, portanto, seguindo uma distribuição gaussiana. Já a outra, sugere que a pressão do arco 
apresenta uma distribuição radial exponencial dupla (ou de Laplace). Diante disso, e das informações presentes na literatura, segundo as quais a distribuição radial de pressão do arco tem influência direta sobre o formato da poça de fusão [13], foram realizados ensaios com o intuito de levantar a distribuição radial da pressão do arco. O resultado destes ensaios é apresentado na Figura 8.

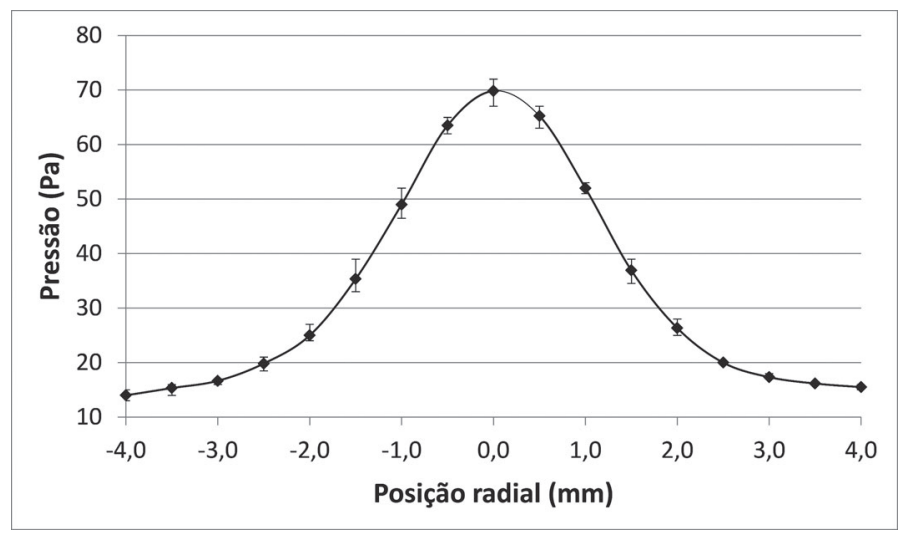

Figura 8. Distribuição radial da pressão do arco

Conforme pode ser visto, a distribuição de pressão obtida melhor se ajusta a uma curva gaussiana característica e, portanto, de acordo com o pressuposto de que a distribuição radial de pressão está intimamente relacionada com as distribuições de corrente e velocidade do jato de plasma. Este resultado está de acordo com os obtidos em trabalhos teóricos [12] e experimentais [1] disponíveis na literatura, ao mesmo tempo em que discorda de outros $[13,14]$ que obtiveram uma distribuição radial de pressão conforme uma curva exponencial dupla. Diante destas divergências, acredita-se que a distribuição da pressão do arco deva sofrer influência de parâmetros como a distância eletrodopeça, intensidade da corrente de soldagem e as características geométricas do eletrodo (diâmetro e ângulo de afiação). Necessitando-se, assim, dar continuidade ao estudo iniciado neste trabalho a fim de melhor compreender o seu comportamento.

\section{Conclusões}

Diante do desenvolvimento realizado e dos resultados obtidos nos ensaios empregando o dispositivo concebido para a medição da pressão do arco, pode-se concluir que:

- O dispositivo concebido se mostrou adequado para realizar a medição da pressão do arco e a avaliação da sua distribuição;

- Pode-se inferir que a qualidade metrológica do dispositivo de medição é elevada, haja vista a repetitividade das medições e a coerência nos resultados encontrados.

- A pressão do arco é fortemente influenciada pela distância eletrodopeça e, em menor grau, pelo tamanho do bocal de gás;

- A distribuição radial da pressão do arco obtida melhor se ajusta a uma curva gaussiana;

- Partindo do pressuposto de que a penetração da solda e a ocorrência de defeitos no cordão obtidos no processo TIG estão intimamente relacionadas com a pressão do arco, o dispositivo desenvolvido demonstrou ser uma importante ferramenta para subsidiar a escolha dos parâmetros de soldagem de acordo com as características geométricas desejadas para o cordão de solda e características operacionais do processo.

\section{Agradecimentos}

Os autores agradecem ao POSMEC - Programa de PósGraduação em Engenharia Mecânica da Universidade Federal de Santa Catarina e à empresa IMC Soldagem.

\section{Referências Bibliográficas}

[1] LIN, M. L.; EAGAR, T. W. Pressures Produced by Gas Tungsten Arcs. Metallurgical Transactions B, v. 17B, p. 601606, Set 1986.

[2] LEE, S. Y. A. N. S. J. A numerical analysis of a stationary gas tungsten welding arc considering various electrode angles. Welding Journal, v. 75, p. 269-279, Set 1996.

[3] LANCASTER, J. F. The Physics of welding. Ireland: Physics technologic, v. 15, 1984. 73-79 p.

[4] WENDELSTORF, J.; DECKER, I.; WOHLFAHRT, H. TIG and PLASMA arc modelling: A survey. in Mathematical Modelling of Weld Phenomena 3, London, 1996.

[5] WU, C. S.; USHIO, M.; TANAKA, M. Modeling the anode boundary layer of high-intensity argon arcs. Computational Materials Science, v. 15, p. 302-310, 1999.

[6] BINI, R.; MONNO, M.; BOULOS, M. I. Numerical and experimental study of transferred arcs in argon. Journal of Physics D: Applied Physics, v. 39, p. 3253-3266, 2006.

[7] HSU, K. C. . E. K. A. P. E. Study of the free-burning highintensity argon arc. Journal of Applyed Physics, v. 54, p. 12931301, 1983.

[8] WU, C. S. . U. M. A. T. M. Analysis of the TIG welding arc behavior. Computational Materials Science, v. 7, p. 308-314, 1997.

[9] FAN, D.; USHIO, M.; MATSUDA, F. Numerical Computation of Arc Pressure Distribution. Transaction of JWRI, v. 15, n. 1, p. 1-5, 1986.

[10] ZHANG, G.; LENG, X.; WU, L. Physics characteristic of coupling arc of twin-tungsten TIG welding. Transactions of Nonferrous Metals Society of China, v. 16, p. 813-817, 2006.

[11] MENDEZ, P. F.; EAGAR, T. W. Penetration and defect formation in high-current arc welding. Welding Journal, v. 82, p. 296-306, Out 2003.

[12] FAN, H. G.; SHI, Y. W. Numerical simulation of the arc pressure in gas tungsten arc welding. Journal of Materials Processing Technology, v. 61, p. 302-308, 1996.

[13] SUN, Q. et al. The arc characteristic of ultrasonic assisted TIG welding. China Welding, v. 17, p. 52-57, 2008.

[14] ONUKI, J. et al. Development os A New High-Frequency, High-Peak Current Power Source for High Constricted Arc Formation. Japanese Journal Applyed Physics, v. 41, p. 58215826, Set 2002. 
[15] FAN, H. G.; SHI, Y. W.; NA, S. J. Numerical analysis of the arc in pulsed current gas tungsten arc welding using a boundaryfitted coordinate. Journal of Materials Processing Technology, v. 72, p. 437-445, 1997.

[16] MPXV7002DP. Freescale Semiconductor, 2013. Disponivel em: $\quad<$ http://www.freescale.com/files/sensors/doc/data_sheet/ MPXV7002.pdf $>$. Acesso em: 05 mar. 2013.

[17] AWS. Welding Handbook. $8^{\text {a }}$ Ed. ed. [S.1.]: AWS, v. 2: Welding Processes, 1991.

[18] GOODARZI, M.; CHOO, R.; TOGURI, T. M. The effect of the cathode tip angle on the GTAW arc and weld pool: I. Mathematical model of the arc. Journal of Physics D: Applyed Physics, v. 30, p. 2744-2756, 1997. 